\title{
Mercado inmobiliario y acceso a la vivienda formal en la Ciudad de Buenos Aires, y su contexto metropolitano, entre 2003 y 2013
}

Luis Baer. Universidad de Buenos Aires, Buenos Aires, Argentina.

Mark Kauw. Universidad de Buenos Aires, Buenos Aires, Argentina.

RESUMEN | El sostenido crecimiento económico con inclusión social y la notable expansión de la oferta residencial privada y la de interés social de la última década no fueron acompañados por una mejora en el acceso al suelo y la vivienda en las ciudades de Argentina. Por el contrario, el problema habitacional y de acceso al suelo formal, bien ubicado, con buenos servicios y ambientalmente seguro, se ha agravado. La Región Metropolitana de Buenos Aires (RMBA) es una de las ciudades del país donde más se manifiesta esta paradoja. En este artículo se desarrollan las bases conceptuales y empíricas para comprenderla. El funcionamiento de los mercados de suelo y el desarrollo inmobiliario de la RMBA será analizado en el período 2003-2013 en relación con el contexto macroeconómico, el esfuerzo monetario para la compra y alquiler de una vivienda formal y determinadas lógicas de desarrollo urbano.

PALABRAS CLAVE | mercado de suelo, mercado inmobiliario, vivienda.

ABSTRACT | The sustained economic and social inclusion growth along with the noticeable expansion of social and private housing supply over the last decade have not been accompanied by an improvement in the access to land and housing in the cities of Argentina. On the contrary, the housing problem and the access to well-located formal land, with good facilities and environmentally safe conditions have worsened like never before. The Metropolitan Region of Buenos Aires (RMBA, for its acronym in Spanish) is one of the cities in the country where this paradox is most manifest. In this article conceptual and empirical bases are developed in order to understand the contradiction. The functioning of land markets and the real estate development in the RMBA will be analyzed, considering the period 20032013 in relation to the macroeconomic context, the monetary effort for the acquisition and rent of a formal dwelling and certain logics of urban development.

KEY WORDS | land market, real estate market, housing.

Recibido el 16 de diciembre de 2014, aprobado el 15 de septiembre de 2015

E-mail: L.Baer, luisbaer@yahoo.com.ar | M.Kauw, markkauw@gmail.com 


\section{Introducción}

El crecimiento económico experimentado en la última década en Argentina fue acompañado por la mejoría de numerosos indicadores socioeconómicos, tales como el empleo, la pobreza y la distribución del ingreso. Este contexto expansivo de la economía con inclusión social no fue acompańado por una mejoría de las condiciones de acceso al suelo, la vivienda y la ciudad. Por el contrario, la proliferación de villas y asentamientos, la ocupación de bienes inmuebles, el incremento del alquiler informal, los desalojos forzados, el desplazamiento de la población de bajos ingresos y la inédita presión que ejerce la renta del suelo sobre los ingresos de la población pusieron al descubierto las crecientes dificultades y conflictos para acceder a un hábitat digno. A la vez, hicieron evidente la necesidad de implementar políticas territoriales que regulen los mercados de tierra urbana y el alquiler de vivienda, redistribuyan las rentas del suelo, promuevan el derecho social del hábitat y favorezcan el acceso al equipamiento y los servicios básicos.

La Región Metropolitana de Buenos Aires (RMBA) es una de las ciudades del país donde más se manifiestan estas dificultades habitacionales y la falta de políticas urbanas enfocadas en la inclusión territorial. En la Ciudad de Buenos Aires (свА), el distrito central del aglomerado metropolitano, el aumento de las inéditas restricciones para acceder a una vivienda formal se dio en simultáneo con un desarrollo inmobiliario que expandió la oferta residencial por encima de los niveles registrados décadas atrás. En los municipios del Gran Buenos Aires (GBA) -el resto del aglomerado que se extiende a lo largo de corredores y anillos concéntricos en torno a la СBA-, no solo el desarrollo inmobiliario ha incrementado significativamente la oferta de vivienda, sino que a la vez las soluciones habitacionales llevadas a cabo por el Estado desde 2003 superaron la cantidad acumulada de las tres décadas precedentes (Duarte, 2010). En decir, en la RMBA se han registrado niveles altísimos en cuanto a la ejecución de soluciones habitacionales, al menos en el GBA, y de construcción privada de vivienda en la СвA. A pesar de la notable expansión de la oferta residencial producida tanto desde el sector público como desde el privado, se ha agravado el problema habitacional y de acceso al suelo formal, bien ubicado, con buenos servicios y ambientalmente seguro (Baer, 2011; Cravino, 2012; Centro de Estudios para el Desarrollo Económico Metropolitano [CEDEM], 2012, Del Río, 2012; Di Filippo, 2010).

La persistencia de ciertas políticas y lógicas de desarrollo urbano, el funcionamiento desregulado del mercado inmobiliario, la ausencia (o insuficiencia) de una política de gestión de suelo urbano, la dinámica de algunos factores macroeconómicos, así como el destino del ahorro y los excedentes de ganancia de las actividades más dinámicas de la economía, son parte de los factores explicativos de esta situación paradójica. Contradictoria porque, en ella, el crecimiento económico (con inclusión social) y la expansión de la oferta residencial (tanto privada como de interés social) se dieron en simultáneo con el aumento de las restricciones de acceso a la vivienda formal. Sin lugar a dudas, el alza desmedida de precios del suelo se vincula directamente con los factores explicativos mencionados y contribuye a la comprensión de estas aparentes contradicciones. 
En este artículo se desarrollan las bases conceptuales y empíricas para comprender estos procesos y compartir algunas reflexiones sobre ciertas prácticas de planificación y políticas de suelo que deberían implementarse para garantizar el derecho a la ciudad. El funcionamiento de los mercados de suelo y el desarrollo inmobiliario de la RMBA en diferentes recortes territoriales, durante el período 2003-2013, será analizado en relación con el contexto macroeconómico, el esfuerzo monetario requerido para la compra y alquiler de una vivienda formal y las lógicas predominantes del desarrollo urbano en la actualidad. Por último, se prevé retomar en las conclusiones los aspectos más significativos del funcionamiento de los mercados de suelo y las posibilidades de acceso residencial, para reflexionar sobre el tipo de política urbana que se requiere para conducir el desarrollo metropolitano de Buenos Aires hacia un modelo de ciudad más equitativo, eficiente y sustentable.

\section{Dinámica de precios del suelo en el ámbito metropolitano de Buenos Aires}

La distribución territorial de precios diferenciales del suelo urbano depende de varios factores. La proximidad a las centralidades; las condiciones de accesibilidad según el transporte público y las vialidades; la calidad ambiental, la de los servicios y de la infraestructura urbana; la disponibilidad de "verde público", la contaminación atmosférica, las condiciones edilicias y el nivel socioeconómico son algunos de los atributos urbano-ambientales y socioterritoriales que orientan las decisiones de localización residencial y empresarial. La posibilidad de acceder a las localizaciones que presentan buenos atributos en los aspectos mencionados depende, en lo fundamental, de la disposición de pago por suelo urbano, sea a través de la compra o el alquiler (Morales-Schechinger, 2007). Ahora bien, la mayor parte de la demanda no compite por suelo urbano para su consumo directo, sino por la actividad que le da soporte. En tal sentido, esta demanda, conocida en la literatura como demanda derivada, compite por suelo en función de las expectativas sobre el tipo e intensidad de uso que dicho suelo tolera en términos económicos, urbanísticos y normativos. Es precisamente sobre esta "fertilidad" derivada de la posición relativa de un lote urbano que este tipo de demanda construye expectativas de ganancia económica, y tales expectativas de rentabilidad son precisamente las que estructuran los precios del suelo urbano ${ }^{1}$. Suele decirse, así, que el precio del suelo está determinado por el mejor y máximo uso (Eckert, 1990) o, como lo señala Smolka (1981), por el diferencial de ventajas que proporciona el uso de un suelo por sobre los demás usos. En la misma línea de análisis, Trivelli (2006) sostiene que en cada sitio del espacio urbano existe una diversidad notable de externalidades, y es por ello que el suelo es una mercancía heterogénea que conforma un mercado segmentado y presenta precios diferenciados.

En este artículo, el análisis de la evolución y distribución territorial de los precios del suelo adquiere importancia por la estrecha relación que existe entre la dinámica de precios y oferta de suelo y la asignación efectiva de usos del suelo, es decir, por la influencia determinante de los mercados de suelo en los procesos de estructuración los negocios de terrenos, más que la tierra misma, es el derecho a percibir una renta”. 
urbana y en el funcionamiento general de la ciudad. A ello se suman las condiciones que imponen tanto la estructura territorial de los precios del suelo, como su dinámica temporal, en el acceso a la vivienda de los distintos "mundos urbanos" que conviven en la ciudad más grande del país (Baer, 2011). En este sentido, los mercados de suelo ejercen una influencia notable en las posibilidades que los diferentes estratos socioeconómicos de la población tienen para acceder a viviendas de distinta calidad en suelo urbano, según sea su disposición de pago. Este universo abarca desde las localizaciones que cuentan con los mejores accesos, servicios, equipamiento y espacios verdes, hasta las que carecen de los mínimos estándares urbanístico-ambientales.

Uno de los rasgos más distintivos del mercado inmobiliario de la RMBA en los años transcurridos tras la crisis de 2001-2002 fue el extraordinario incremento de precios del suelo, que superó ampliamente el alza de precios relativos del resto de los bienes y servicios de la economía. En la СвA, el precio promedio de oferta de los terrenos aumentó, entre junio de 2002 y junio de 2014, casi nueve veces, pasando de Us\$ 193 a us\$ 1.682 el metro cuadrado (tabla 1). Este proceso de valorización inmobiliaria no ha sido gradual; por el contrario, ha experimentado tendencias, ritmos y temporalidades que permiten distinguir, a grandes rasgos, cuatro momentos (figura 1). Entre junio de 2002 y el mismo mes de 2008 se dio un alza de precios especialmente significativo, a razón de us\$133 el metro cuadrado por año, y una tasa de variación anual promedio del $32 \%{ }^{2}$. Luego de registrarse un breve amesetamiento entre junio de 2008 y diciembre de 2009, período en el que se registró una tasa del $2 \%$ anual, la evolución del precio promedio retomó su senda de crecimiento hasta alcanzar, a mediados de 2012, valores cercanos a los US\$ 1.700 por metro cuadrado. Si bien en este período la variación anual fue del $16 \%$, significativamente menor a la del período 2002-2008, en términos absolutos se correspondió con las mayores alzas de precios del suelo, a razón de us\$249 el metro cuadrado por año.

Finalmente, durante los dos años que van de junio de 2012 a junio de 2014, el precio promedio del suelo se ha mantenido prácticamente estable, tal como ocurrió entre diciembre de 2009 y junio de 2012. Sin embargo, el amesetamiento de precios del primer período se debió a una retracción coyuntural del mercado inmobiliario relacionada con la crisis financiera global ${ }^{3}$, mientras que la iniciada a mediados de 2012 se originó más bien por causas domésticas; entre ellas, el incremento de las restricciones para la compra libre de dólares ${ }^{4}$ y la desaceleración de la actividad económica.

Se escoge la variación relativa y absoluta de crecimiento medio anual para comparar la intensidad de la evolución de precios del suelo en períodos con diferentes longitudes temporales.

3 Las casusas macroeconómicas y propias del mercado inmobiliario para caracterizar el proceso de valorización inmobiliaria experimentado desde la salida de la crisis de 2001-2002 hasta diciembre de 2008 (Baer, 2011).

4 La medida, conocida como "cepo cambiario", refiere a una serie de restricciones que se fueron imponiendo para la compra de dólares desde octubre de 2011. Una de las medidas más restrictivas se implementó el 5 de julio de 2012, cuando se reforzaron las restricciones de compra de dólares para el ahorro. 
TABLA 1 Indicadores síntesis de la evolución de precios del suelo. CBA, período 2002-2013 ${ }^{(1)}$

\begin{tabular}{|c|c|c|c|c|c|c|c|c|c|c|c|c|c|}
\hline & 2002 & 2003 & 2004 & 2005 & 2006 & 2007 & 2008 & 2009 & 2010 & $201 \mathrm{I}$ & 2012 & 2013 & 2014 \\
\hline $\begin{array}{l}\text { Oferta } \\
\text { (lotes) }\end{array}$ & 107 & 556 & 1.013 & 1.347 & 1.299 & $\mid 1.709$ & 1.773 & 1.418 & 978 & 1.569 & 1.436 & 1.468 & 1.799 \\
\hline $\begin{array}{c}\text { Oferta (hec- } \\
\text { táreas) }\end{array}$ & 5,2 & 31,5 & s/d & 73,1 & 61,3 & 83,0 & 83,0 & 64,0 & 45,9 & 63,6 & 67,6 & 53,4 & 91,2 \\
\hline Promedio ${ }^{(2)}$ & 193 & 318 & 439 & 548 & 758 & 856 & 989 & 1.057 & 1.194 & 1.541 & 1.671 & 1.697 & 1.682 \\
\hline Mediana & 173 & 292 & 356 & 454 & 564 & 707 & 840 & 882 & 1.081 & 1.358 & 1.562 & 1.495 & 1.481 \\
\hline Min & 69 & 127 & 120 & 141 & 213 & 273 & 115 & 258 & 369 & 377 & 302 & 460 & 460 \\
\hline Max & 386 & 1.017 & 1.666 & 1.945 & 2.926 & 3.357 & 2.459 & 3.822 & 2.970 & 3.302 & 4.530 & 4.960 & 4.959 \\
\hline
\end{tabular}

FUENTE ELABORADO CON BASE EN LOS INFORMES TRIMESTRALES DE PRECIOS DEL SUELO DE LA CIUDAD DE BUENOS AIRES (SECRETARÍA DE PLANEAMIENTO, SSPLAN)

NOTAS (I) LOS VALORES DE TODAS LAS VARIABLES CORRESPONDEN AL MES DE JUNIO DE CADA AÑO.

(2) REFIERE A UN PROMEdio AJUSTAdo QUE EXClUYE PUERTO MADERO Y RETIRO, POR LA DISTORSIÓN QUE GENERAN SUS VALORES EXTREMOS (OUTLIERS).

FIGURA 1 Evolución absoluta y relativa del precio promedio ${ }^{1}$ del suelo. CBA, dic. 2002-jun. 2014

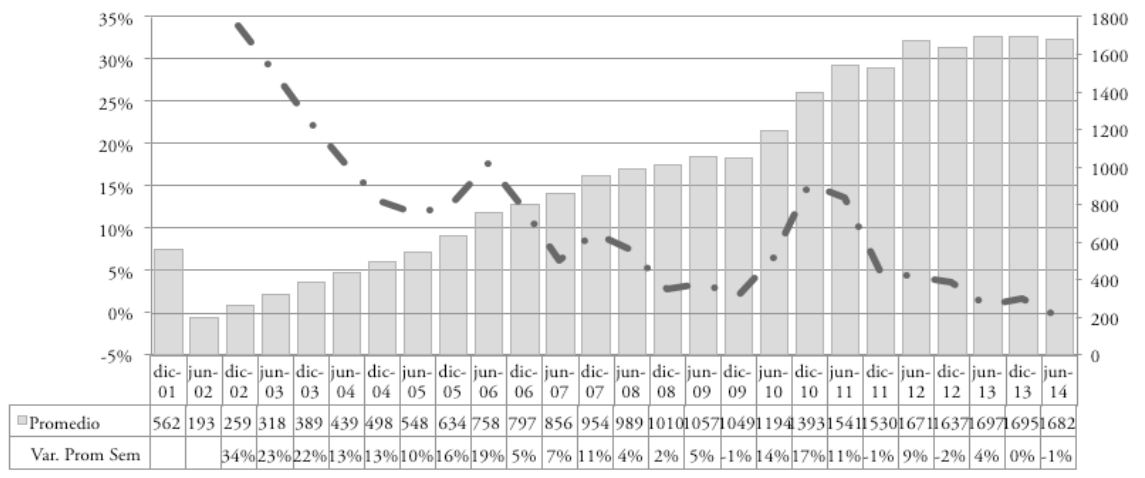

FUENTE ELABORADO CON BASE EN LOS INFORMES TRIMESTRALES DE PRECIOS DEL SUELO DE LA CIUDAD DE BUENOS AIRES (SUBSECRETARÍA DE PLANEAMIENTO, SSPLAN)

NOTA (I) REFIERE A UN PROMEDIO AJUSTADO QUE EXCLUYE PUERTO MADERO Y RETIRO, POR LA DISTORSIÓN QUE GENERAN SUS VALORES EXTREMOS (OUTLIERS).

Otro rasgo distintivo de la dinámica de precios del suelo de la СвA se evidencia a partir del año 2007, cuando comienza a registrarse un achicamiento de la brecha de precios del suelo entre los barrios históricamente más y menos valorizados; a grandes rasgos, los del norte y los del sur. La calidad de los servicios e infraestructura urbana, las posibilidades de aprovechamiento del suelo y las preferencias de localización de los sectores de ingresos medios y altos, así como de ciertos servicios, 
comercios y oficinas, han ido determinando a lo largo del tiempo que los mayores precios del suelo se registren en el Área Central y en el corredor norte de la CBA. Pero durante los últimos seis años se ha identificado un cambio en los ritmos de valorización, que llevó a que la diferencia de precios del suelo entre los barrios del norte y los del sur se estrechara, tras alcanzar un nivel máximo de 3 veces en 2006, a 2,3 desde 2009 hasta la actualidad (figura 2).

FIGURA 2 Evolución de la diferencia de precios del suelo entre Zona Norte ${ }^{(1)}$ y Zona Sur ${ }^{(2)}$

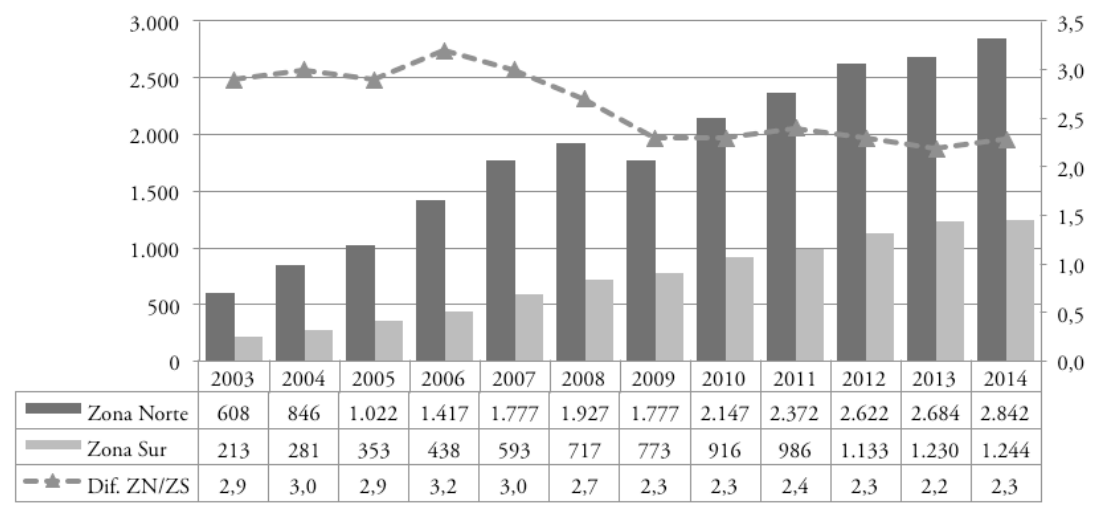

FUENTE ELABORADO CON BASE EN LOS INFORMES TRIMESTRALES DE PRECIOS DEL SUELO DE LA CiUdAd DE BUENOS AIRES (SECRETARÍA DE PLANEAMIENTO, SSPLAN)

NOTAS (I) COMPRENDE LOS BARRIOS SAAVEDRA, NÚÑEZ, COGHLAN, BELGRANO, COLEGIALES, PALERMO Y RECOLETA. ${ }^{(2)}$ COMPRENDE LOS BARRIOS MATADEROS, V. LUGANO, V. RIACHUELO, V. SOldati, PQUe. AVEllaneda, PQUe. CHACABUCO, NUEVA POMPEYA, Boedo, PQUe. PATRICIOS, BARRACAS, SAN CRISTÓBAL, CONSTITUCIÓN, LA BOCA Y SAN TELMO.

Esta convergencia de precios del suelo entre norte y sur ha sido destacada por el Gobierno de la Ciudad como un cambio de tendencia en cuanto a la histórica desigualdad socio-territorial que caracteriza a la ciudad (Secretaría de Planeamiento [sSplan], 2013). Pero el achicamiento de la brecha de precios se debe a una mayor intensidad de valorización de los barrios del sur, antes que a una disminución de precios en la zona norte. Es por ello que también se ha considerado este proceso de convergencia de precios del suelo como un retroceso en términos del derecho a la ciudad, debido al impacto que genera el aumento de la renta del suelo en los sectores de ingresos medios y bajos que habitan en el sur de la ciudad y no pueden afrontar los precios de los alquileres residenciales y comerciales, provocando así la expulsión de numerosas familias de bajos ingresos (Jajamovich \& Menazzi, 2013). La disminución de la brecha de precios del suelo podría estar manifestando, así, un proceso de gentrificación en el sur de la ciudad, específicamente en las áreas de renovación urbana que impulsa el gobierno de la ciudad en torno al Distrito Tecnológico en Parque Patricios, el de las Artes en La Boca y el del Diseño en Barracas5.

5 Sobre los actuales procesos de gentrificación en la ciudad, véanse los artículos de Silva (2013), Salinas Arreortua (2013), y los artículos compilados en Hidalgo y Janoschka (2014). Sobre los 
A escala metropolitana, también es posible realizar un análisis aproximado de la evolución y estructura de precios del suelo, pero solo a partir del año $2004^{6}$. La extensión de la mancha urbana y la diversidad urbanístico-ambiental de la RMBA determinan una significativa dispersión territorial de precios del suelo, la cual pone nuevamente en evidencia las limitaciones de las medidas de tendencia central para analizar el valor de la tierra. No obstante, se puede realizar una comparación aproximada sobre la evolución de precios promedio por grandes recortes territoriales; por ejemplo, según anillos concéntricos desde la СвA hacia la periferia metropolitana (coronas) $^{7}$ y entre los tres grandes corredores radiales (sur, oeste y norte) ${ }^{8}$. El primer criterio, por la influencia que ejerce la distancia a la СвA en la estructuración de precios a escala metropolitana; el segundo, por los variados atributos urbanísticos y socioterritoriales que fue adquiriendo cada uno de los corredores en torno a los principales accesos viales y el ferrocarril. La disminución de precios hacia los bordes y a través de los corredores metropolitanos es una tendencia general, que se interrumpe ante la presencia de ciertos enclaves urbanos, centralidades tradicionales (a veces coincidentes con las ciudades cabecera de los municipios metropolitanos y estaciones del ferrocarril) y nuevas centralidades periféricas?

Las distintas coronas de la RMBA experimentaron una notable alza de precios del suelo entre los años 2004 y 2014, todas con tasas de variación promedio anual por encima de la propia сва (que, para el mismo período, registró un aumento del $15,3 \%)$, pero principalmente la segunda corona, que registró una tasa de variación del 21,8\% (figura 3). En términos de valores, el precio promedio por metro cuadrado de los lotes en la primera corona alcanzó para septiembre de 2014 los Us $\$ 630$ el metro cuadrado, esto es, 2,4 veces el precio promedio registrado para la segunda corona (uS\$266 $\mathrm{el} \mathrm{m}^{2}$ ); y poco más de seis veces la diferencia con la tercera corona (US\$ $101 \mathrm{el} \mathrm{m}^{2}$ ). El comportamiento de las tasas de valorización ha contribuido a estrechar la diferencia de precios del suelo entre los municipios contiguos a la Сва y los de la segunda corona, pues en 2004 la diferencia era de 3,2 veces.

procesos de renovación urbana en el sur de la ciudad, sus impactos socioterritoriales y entramado de actores sociales, se sugieren los artículos de Rodríguez y Virgilio (2015) y Herzer (2012).

$6 \quad$ No se cuenta con información para los ańos previos.

7 La Corona 1 abarca los municipios de San Isidro, Vicente López, Tres de Febrero, San Martín, Hurlingham, Ituzaingó, Morón, Ezeiza, Esteban Echeverría, Almirante Brown, Lomas de Zamora, Lanús, Quilmes, Avellaneda y La Matanza. La Corona 2 está conformada por San Fernando, Tigre, Malvinas Argentinas, San Miguel, José C. Paz, Moreno, Merlo, Presidente Perón, Florencio Varela y Berazategui. Los municipios de la Corona 3 son: Campana, Escobar, Exaltación de la Cruz, Pilar, Luján, General Rodríguez, Marcos Paz, General Las Heras, Cañuelas, San Vicente, Brandsen, La Plata, Ensenada y Berisso.

8 El Corredor Oeste abarca los municipios de Ituzaingó, Morón, La Matanza, Merlo, Moreno, Marcos Paz, General Rodríguez Lujan y General Las Heras. El Corredor Norte está compuesto por los municipios de San Isidro, Vicente López, Tres de Febrero, San Martín, Hurlingham, San Fernando, Tigre, Malvinas Argentinas, San Miguel, José C. Paz, Campana, Escobar, Exaltación de la Cruz y Pilar. El Corredor Sur comprende los municipios de Ezeiza, Esteban Echeverría, Almirante Brown, Lomas de Zamora, Lanús, Quilmes, Avellaneda, Presidente Perón, Florencio Varela y Berazategui, Cañuelas, San Vicente, Brandsen, La Plata, Ensenada y Berisso.

9 Sobre la dinámica de la nueva centralidad metropolitana en los años dos mil, véase Vecslir y Baer (2011). 
En cuanto a la evolución de precios promedio según corredor metropolitano, sobresale la intensa valorización experimentada por el corredor sur (figura 4). En efecto, en este corredor se ha registrado, para el período 2004-2014, una tasa de valorización anual del $17,7 \%$, muy por encima de las verificadas en los corredores norte y oeste, de $8,9 \%$ y $10,4 \%$, respectivamente. Esto se debe a los elevados precios del suelo alcanzados en los últimos años en ciertas localidades del corredor sur en torno a las estaciones ferroviarias de Lanús, Banfield, Lomas de Zamora, Adrogué y Burzaco. El trazado del ferrocarril como factor de influencia en la estructuración territorial de precios del suelo también adquiere suma importancia en el corredor oeste, explicando, junto con otros factores, precios relativamente altos en localidades como Ramos Mejía, Haedo y Castelar. En el corredor norte el ferrocarril ejerce cierta influencia, pero deben agregarse los ejes viales conformados por el Acceso Norte, las avenidas Maipú / Santa Fe / Centenario y del Libertador, además de la proximidad al Río de la Plata (en ciertos sectores). En suma, la gran segmentación que ha caracterizado históricamente el mercado de suelo en su escala metropolitana persiste. Sin embargo, se han registrado algunos cambios de tendencia durante el proceso de valorización inmobiliaria estudiado, al estrecharse parcialmente las tradicionales brechas de precios del suelo entre las áreas más y las menos valorizadas. Esto ha ocurrido, al menos, durante el período 2008-2013, cuando los precios del suelo del norte y sur de la свA, la primera y segunda corona metropolitana y del corredor sur respecto al corredor norte, tendieron a converger.

FIGURA 3 Evolución de precios promedio del suelo (en us $\$ / \mathrm{m}^{2}$ ), tasa de valorización anual (TVA) por corona de la RMBA. Período 2004-2014

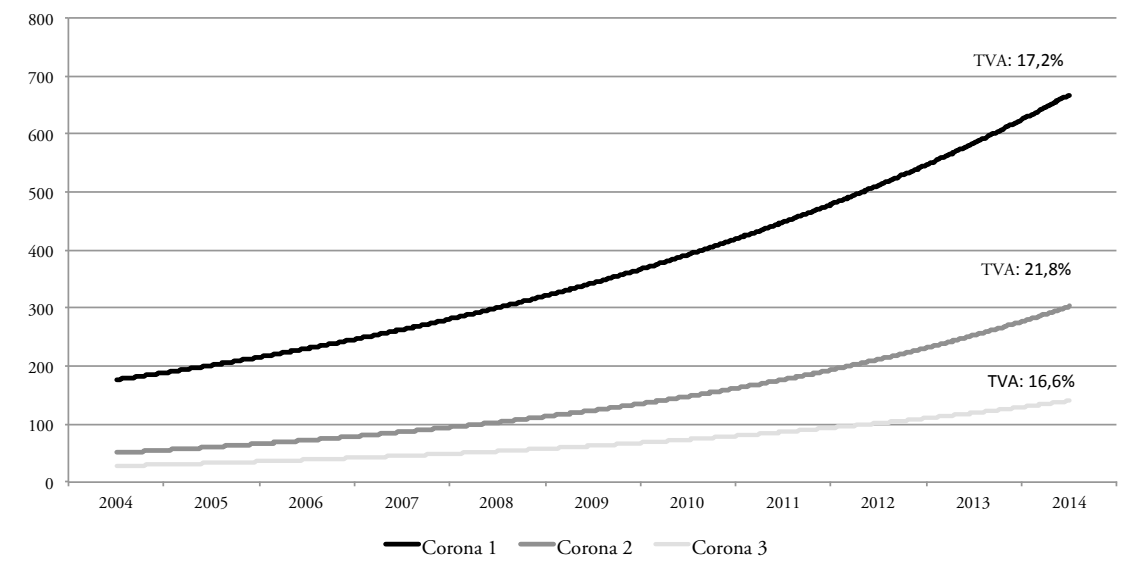

FUENTE ELABORADO CON BASE EN LOS INFORMES TRIMESTRALES DE PRECIOS DEL SUELO DE LA CIUdAd DE BUENOS AIRES (SECRETARÍA DE PLANEAMIENTO [SSPLAN])

NOTA SE HA DECIDIDO UTILIZAR LA LÍNEA DE TENDENCIA EXPONENCIAL PARA FACILITAR LA LECTURA DE LA TENDENCIA GENERAL DE VALORIZACIÓN CORRESPONDIENTE A CADA CORONA. 
FIGURA 4 Evolución de precios promedio del suelo (en US $\$ / \mathrm{m}^{2}$ ), tasa de valorización anual (TVA) por grandes corredores de la RMBA. Período 2004-2013

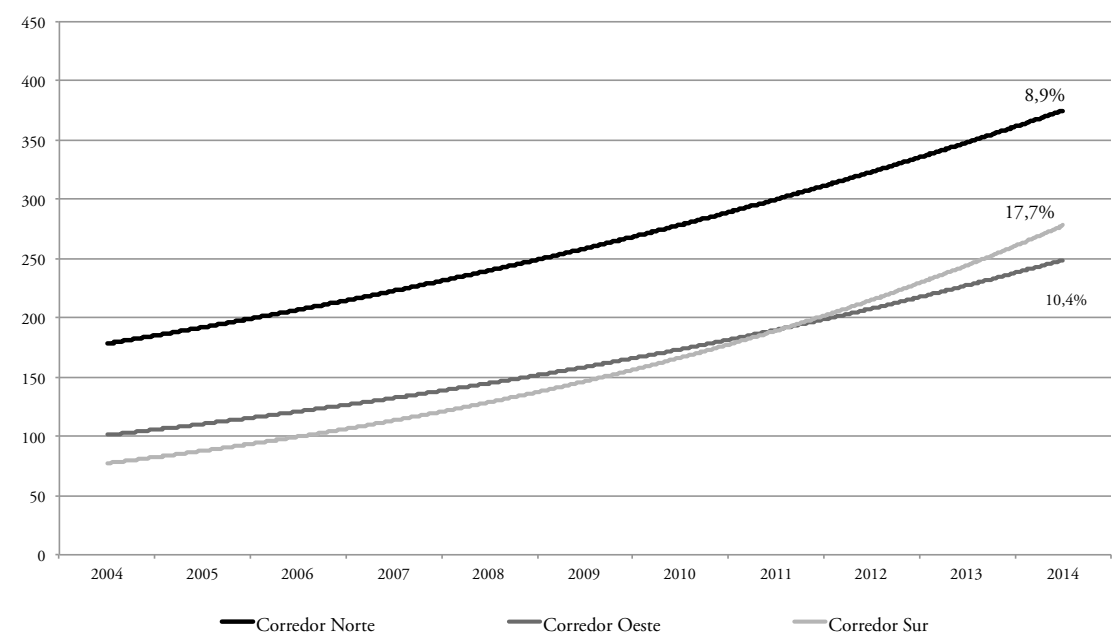

FUENTE ELABORADO CON BASE EN LOS INFORMES TRIMESTRALES DE PRECIOS DEL SUELO DE LA CIUDAD DE BUENOS AIRES (SECRETARÍA DE PLANEAMIENTO [SSPLAN])

NOTA SE HA DECIDIDO UTILIZAR LA LÍNEA DE TENDENCIA EXPONENCIAL PARA FACILITAR LA LECTURA DE LA TENDENCIA GENERAL DE VALORIZACIÓN CORRESPONDIENTE A CADA CORREDOR METROPOLITANO.

\section{Evolución reciente del desarrollo inmobiliario en la Ciudad de Buenos Aires}

La importancia que ha adquirido la demanda derivada en la asignación diferencial de precios del suelo (especialmente en ámbitos urbanos consolidados y con cierta densidad) justifica la decisión de analizar la dinámica del desarrollo inmobiliario. Los permisos de construcción solicitados para construir (cuánto, qué, dónde y cuándo ${ }^{10}$ ofrecen una evidencia empírica confiable para rastrear el suelo por el cual compitieron los desarrolladores inmobiliarios y las expectativas sobre la demanda final que esperaban satisfacer con los emprendimientos. Este capítulo pretende ser un aporte para develar estas inquietudes.

Un primer rasgo que destacar es el notable dinamismo de la construcción experimentado en la свA a lo largo de los últimos diez ańos. Luego de la crisis de 2001-2002, la superficie de los permisos de construcción nueva (sin ampliaciones) $)^{11}$ mantuvo un crecimiento sostenido hasta superar en el año 2005, con $1.954 .598 \mathrm{~m}^{2}$, el promedio del período 1990-2001 (1.362.512 $\left.\mathrm{m}^{2}\right)$ y del período 2003-2013 $\left(1.774 .129 \mathrm{~m}^{2}\right)$.

10 Lamentablemente solo se dispone de información desagregada de los permisos de construcción por uso, categoría residencial y barrio para el caso de la СвA.

11 Los permisos de obra engloban tanto a las construcciones nuevas como a las ampliaciones. El dinamismo del desarrollo inmobiliario, y su influencia en la formación de los precios del suelo, se asocian fundamentalmente con los permisos de obra de construcciones nuevas. 
La evolución de los permisos de construcción es significativamente más sensible que la dinámica de precios del suelo frente a la volatilidad de la economía y pone de manifiesto el carácter procíclico de la construcción. La figura 6 es elocuente y permite distinguir las fases tanto de auge como de contracción del desarrollo inmobiliario, siendo el período 2005-2008 el ciclo de mayor dinamismo. A partir de 2008, la dinámica constructiva disminuyó a la par de la desaceleración de los precios del suelo. El impacto de la crisis financiera internacional en la economía local también comenzaba a hacerse notar en el sector. Si bien para el año 2011 se registró un repunte de la actividad, ya en 2012 se retomó la senda descendente, hasta registrarse en 2013 la menor cantidad de superficie autorizada para construir, con excepción de 2002, de los últimos veinticuatro años. Esta brusca caída, sumada a otros indicadores del sector, tiene una relación directa con la menor intensidad de la actividad económica, en general, y el efecto del denominado cepo cambiario, en particular. El promedio anual de la construcción nueva entre 2009 y 2013 cayó un 28\% en comparación con el período 2003-2008; no obstante, la dinámica reciente supera el comportamiento de la década de los noventa, con $106.435 \mathrm{~m}^{2}$ construidos por año.

Si se analizan los usos del suelo que el desarrollo inmobiliario concretó mediante tales permisos, puede constatarse que el $70 \%$ de la superficie autorizada para construir en el período 1990-2001 (con un promedio anual de casi 1 millón de $\mathrm{m}^{2}$ ), fue destinado al uso residencial. Para el período 2003-2013 (con un promedio anual de casi 1,5 millones de $\mathrm{m}^{2}$ ), dicha incidencia había ascendido a un $83 \%$, acumulando un total de 16,2 millones de $\mathrm{m}^{2}$. La mayor incidencia del uso residencial en los años dos mil no solo se vincula con la concentración del desarrollo inmobiliario en la producción de vivienda, sino con la mayor importancia que tuvo la construcción de grandes centros comerciales (hipermercados y shoppings centers) en los noventa.

FIGURA 5 | Evolución de la superficie autorizada para construcciones nuevas (millones de $\mathrm{m}^{2}$ ) por uso e incidencia de uso residencial. CBA, 1990-2013

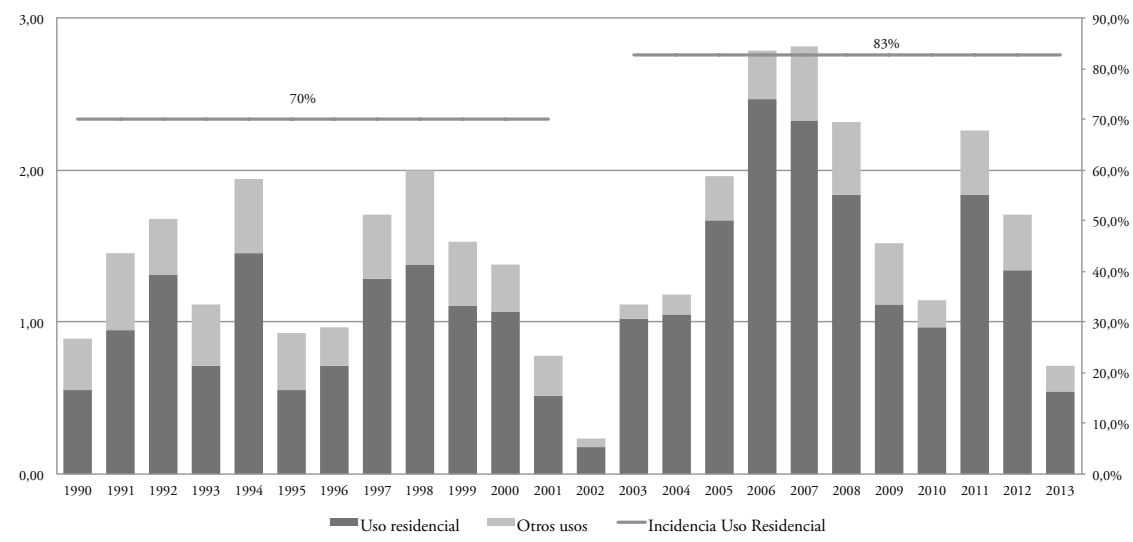

FUENTE ELABORADO CON DATOS DE LA DIRECCIÓN GENERAL DE REGISTRO DE OBRAS Y CATASTRO 
Lo primero que se distingue cuando se analiza la evolución de la composición de la superficie autorizada para uso residencial es el incremento de la incidencia de la vivienda multifamiliar por sobre la vivienda unifamiliar (del 92\% en 1990-2001 al 98\% en 2003-2013). El aumento de la incidencia de la vivienda multifamiliar no es indiferente a la dinámica territorial de los mercados de suelo, porque supone una mayor presión de la demanda derivada sobre aquellas zonificaciones que, por normativa, soportan una mayor edificabilidad. De este modo, la concentración territorial del desarrollo inmobiliario sobre ciertas zonas de la ciudad tiende a traducirse en mayores alzas de precios del suelo.

Otro cambio importante del desarrollo inmobiliario de la última década refiere al tamaño promedio de la vivienda. Mientras en el decenio 1991-2001 la superficie media de la unidad de vivienda multifamiliar fue de $111 \mathrm{~m}^{2}$, para el período 2003-2013 dicho promedio se redujo a $96 \mathrm{~m}^{2}$. Sin embargo, es a partir de 2009 cuando se hace notar fuertemente la tendencia hacia la producción de vivienda con menores superficies promedio - por cierto, de las más reducidas en la historia de la construcción residencial de la ciudad-, que se manifiesta en la creciente oferta de vivienda nueva de uno y dos ambientes. Se trata de un mayor aprovechamiento del suelo $^{12}$, considerando la obtención de renta en unidades de menor tamaño, el uso de la vivienda como inversión en un contexto de creciente inquilinización de los hogares y una demanda inmobiliaria que, en el caso de poder comprar vivienda, solo puede volcarse a la "vivienda chica".

También se distinguen cambios sustanciales al desagregar el uso residencial de acuerdo con las cuatro categorías en que se registran los permisos de construcción, de menor a mayor estándar: sencilla, confortable, lujosa y suntuosa (Dirección General de Estadísticas y Censos [DGEyc], 2011). Lo más llamativo de la comparación de la década de los noventa con ambos momentos del período 2003-2013 es el aumento de la incidencia de la vivienda suntuosa ${ }^{13}$, especialmente cuando se la contrasta con el subperíodo 2003-2008, al pasar del 19\% al 42\% (figura 6). El espacio residencial solicitado para atender a los sectores de altos ingresos ha ido perdiendo protagonismo desde entonces, lo que se refleja en la merma de 10 puntos porcentuales para el quinquenio 2009-2013. Como contrapartida, y a pesar de la caída general de la actividad, se ha registrado un importante aumento relativo (y también absoluto) de la vivienda sencilla, que ha pasado del $21 \%$ al 36\%. Esta disminución del estándar de la vivienda se relaciona con la reducción de la superficie promedio del espacio residencial solicitado para construir y, junto a la variación de la incidencia de la vivienda suntuosa, manifiesta un cambio de tendencia del desarrollo inmobiliario al interior del ciclo de valorización del suelo en el período 2003-2013, que también se observa al analizar el destino de los permisos de construcción por barrio.

12 El mayor uso refiere al uso del suelo que puede pagar el mayor precio en la competencia con otros usos por la compra de un terreno específico (Morales-Schechinger, 2005).

13 La vivienda categorizada como suntuosa se corresponde, en gran medida, con la tipología residencial dada a conocer por el marketing inmobiliario como Torres Deluxe, Torres Premium o Torres Country (Szajnberg, 2006). 
FIgURA 6 | Promedio anual de $\mathrm{m}^{2}$ y porcentaje de superficie autorizada para construir vivienda por categoría. СBA, períodos 1991-2001, 20032008 y 2009-2013

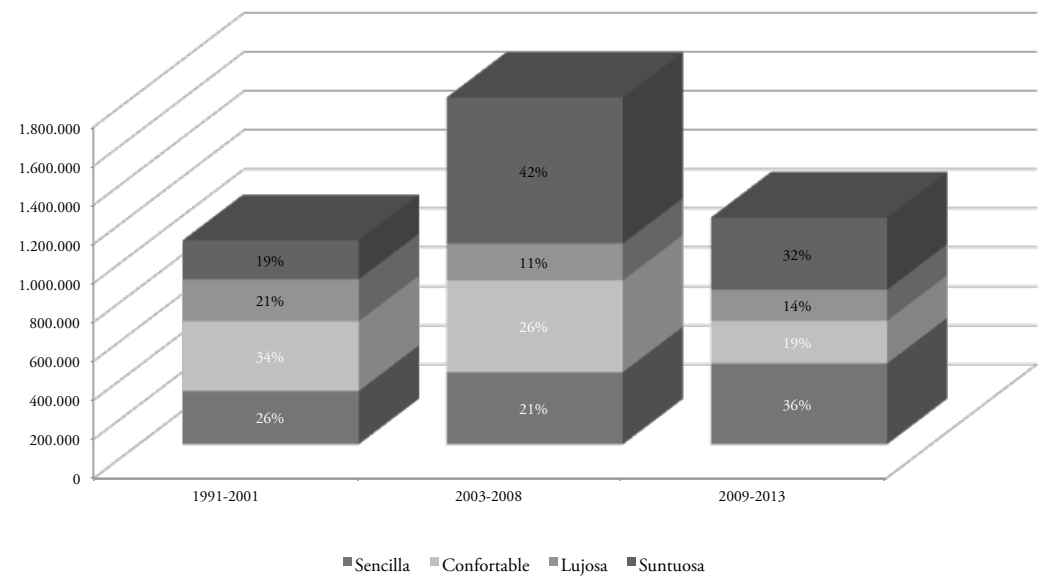

FUENTE ELABORADO CON DATOS DE LA DIRECCIÓN GENERAL DE REGISTRO DE OBRAS Y CATASTRO

En efecto, la preferencia del desarrollo inmobiliario por construir vivienda amplia y suntuosa en el período 2003-2008 se ha correspondido con una notable concentración territorial: solamente cinco barrios explicaron el $47 \%$ del espacio residencial autorizado para construir en dicho período, mientras que solo un barrio, Palermo, dio cuenta del $15 \%$. La selectividad territorial del desarrollo inmobiliario suele variar con el tipo de vivienda que se pretende construir; y eso es precisamente lo que sucedió entre 2009 y 2013 cuando, en simultáneo con el aumento de la incidencia de la vivienda sencilla de uno o dos ambientes y la disminución de la incidencia de la vivienda suntuosa de mayores superficies, se registró un principio de desconcentración territorial de la superficie residencial autorizada para construir. En efecto, los cinco barrios más dinámicos, que habían concentrado casi la mitad de la construcción en el período 2003-2008, perdieron su peso relativo en el período 2009-2013 y, a la vez, registraron menores intensidades de valorización del suelo que la mayoría de los barrios.

Ahora bien, los diferentes patrones de desarrollo inmobiliario no son neutrales en lo que refiere a la dinámica de precios del suelo. El período 2003-2008 se ha distinguido por la expansión del espacio residencial para sectores de ingresos altos y medio-altos con capacidad de compra (pagando al contado) de vivienda suntuosa, relativamente amplia y ubicada casi exclusivamente en los barrios tradicionales de alta renta. Esta tendencia del mercado contribuye a explicar que en el eje norte, en Puerto Madero y en ciertos barrios del eje oeste de la ciudad se hayan registrado los mayores aumentos de precios del suelo. Una vez agotado este ciclo de valorización por la saturación de la demanda de este producto inmobiliario, la escasez de suelo en estas porciones de la ciudad y los elevados precios de los terrenos allí en oferta, el desarrollo inmobiliario reorientó sus preferencias localizacionales y tipológicas 
hacia áreas de la ciudad menos valorizadas, estándares de vivienda de menor categoría y unidades de vivienda con menores superficies. De este modo, transcurridos los efectos de la crisis financiera internacional en la economía local, el precio del suelo no solo retomó su senda de crecimiento, sino que lo hizo con características diferentes a las del período precedente. En este proceso, el hecho más sobresaliente estuvo en los cambios en las tasas de valorización entre los barrios más y menos valorados de la ciudad y, por lo tanto, el achicamiento de la brecha de precios entre el norte y sur. El incremento de la competencia de la demanda por suelo en el sur de la ciudad y las expectativas de algunos propietarios, son parte explicativa de esa mayor valorización, que acentuó las dificultades de acceso formal a la vivienda.

A partir de 2012, el ciclo alcista de precios del suelo muestra su agotamiento luego de una notable caída de la construcción privada, que se ve arrastrada, en lo fundamental, por el desdoblamiento del mercado del dólar ${ }^{14}$, que se incrementa a partir del reforzamiento del llamado "cepo cambiario".

\section{Restricciones crecientes para el acceso a la vivienda formal en la Ciudad de Buenos Aires}

La evolución del esfuerzo monetario para la compra y alquiler de vivienda, así como determinadas características del mercado hipotecario, constituyen algunas variables útiles para dimensionar las condiciones de acceso residencial por el lado de la demanda final. El desplome de la demanda derivada de tierra para el desarrollo inmobiliario tiene, desde luego, relación directa con la retracción de la demanda final de vivienda en el contexto de la desaceleración económica característica de los últimos años. Este proceso se manifiesta en la notable caída de las operaciones de compraventa de inmuebles realizadas en la СвA: para los años 2012 y 2013 se registró la menor cantidad de operaciones de las últimas décadas y, con excepción de los ańos 2002 y 2003, la menor incidencia (7\%) de las operaciones encauzadas a través del crédito hipotecario ${ }^{15}$ (figura 7 ).

La concepción clásica de la ley de oferta y demanda sostiene que, ante la contracción de la capacidad de la demanda, los precios bajan. Sin embargo, en mercados sumamente imperfectos y desregulados como el inmobiliario, esta premisa teórica está lejos de cumplirse, especialmente en lo que refiere a los precios del suelo, que se han mantenido constantes a lo largo de los años de fuerte caída de la demanda

14 La aparición y distanciamiento del dólar ilegal respecto al dólar oficial se convierte en un factor inflacionario con impacto en los precios de construcción. Otra razón de aumento de precios refiere a la estructura de mercado oligopólica de los insumos difundidos (acero, aluminio y cemento), que favorece la imposición de precios desproporcionados en las cadenas de valor asociadas al sector (Zaiat, 2014).

15 La baja proporción de las hipotecas ha sido una constante a lo largo del ciclo de valorización inmobiliaria iniciado tras la crisis de 2001-2002. Mientras en el período 1993-2001 esta promedió un 34\%, para el período 2003-2013 la proporción de las hipotecas se contrajo al 12\%. Otra diferencia entre ambos períodos se refleja en la evolución de las incidencias, registrándose para la década de los noventa una evolución constante con solo 3 puntos porcentuales de variación, mientras que para la de los dos mil una evolución sumamente variable, con un rango de variación de 14 puntos porcentuales. 
derivada (desarrollo inmobiliario) y final (consumidores residenciales) de vivienda nueva. Para el caso de las unidades de vivienda por estrenar, luego de alcanzar un pico máximo de precios en el tercer trimestre de 2012, también se ha registrado una relativa estabilidad de precios, aunque algunos barrios experimentaron pequeños ajustes. Los valores de venta de las unidades de vivienda por estrenar y del suelo urbano no han disminuido, porque el ajuste se dio más bien por el flujo de oferta antes que por la vía de los precios. Otra forma de adaptación a la coyuntura económica se dio a través del tamańo de las unidades construidas. En cualquier caso, se trata de las estrategias llevadas a cabo en el desarrollo inmobiliario para mantener la rentabilidad ante el aumento de las restricciones de acceso residencial, que se dio a lo largo de todo el ciclo de valorización inmobiliaria.

FIGURA 7 Actos notariales de compra venta de inmuebles e incidencia (\%) de hipotecas. СВA, 1993-2012

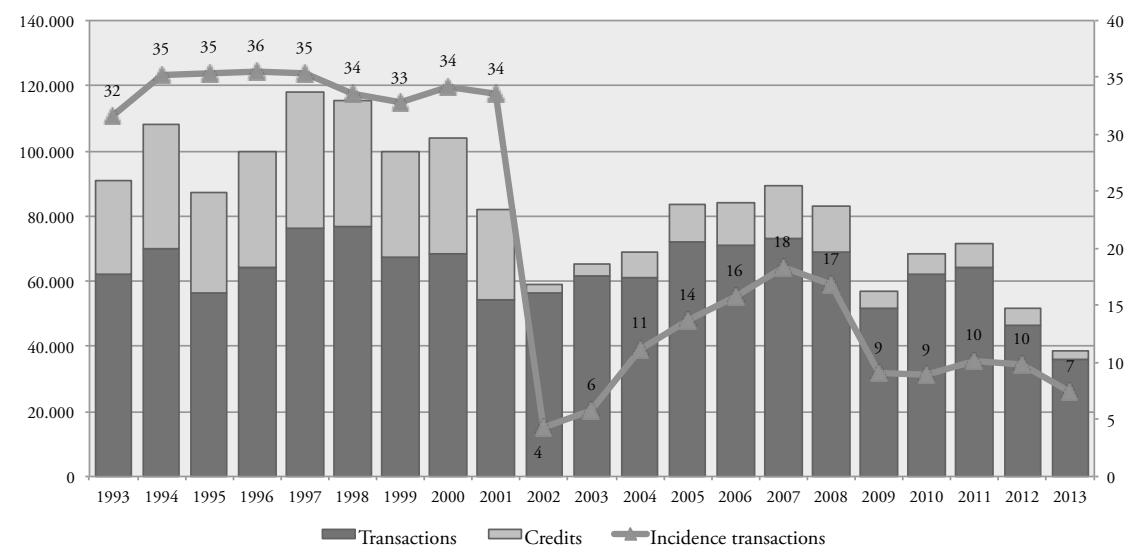

FUENTE COLEGIO DE ESCRIBANOS DE LA CIUDAD DE BUENOS AIRES

El incremento de precios de la vivienda experimentado tras la crisis de 2001-2002 continuó, en niveles desproporcionados, incluso a partir de 2006, cuando ya se habían superado los precios promedio en dólares de la década de los noventa. De este modo, los valores promedio de los departamentos por estrenar de dos y tres ambientes llegaron a duplicarse entre 2006 y 2013. La presión creciente generada por la valorización inmobiliaria se ve claramente en la evolución del esfuerzo monetario que deben hacer las personas para la compra de vivienda. La tabla 2 permite visualizar el fuerte aumento de la cantidad media de ingresos que deben reunirse para la compra de una misma unidad de vivienda (incluso en los barrios que más vieron incrementar su oferta), especialmente entre 2009 y 2013, período en el cual se debió destinar entre 3,4 y 5,5 más años de ingresos medio (AIM) para la compra de una unidad. 
TABLA 2 Precio promedio $\left(\mathrm{U} \$\left(\mathrm{~m}^{2}\right)\right.$ de departamentos de dos ambientes por estrenar y cantidad de ańos ingresos medio (AIM) para su adquisición. СBA, octubre de 2006, 2009 y 2013

\begin{tabular}{|c|c|c|c|c|c|c|c|c|c|c|c|c|c|}
\hline \multirow{3}{*}{\begin{tabular}{|l} 
Barrio \\
Caballito
\end{tabular}} & \multicolumn{3}{|c|}{2006 (OCTUBRE) } & \multicolumn{3}{|c|}{2009 (OCTUBRE) } & \multicolumn{4}{|c|}{$20{ }_{3}$ (OCTUBRE) } & \multirow{3}{*}{$\begin{array}{c}\text { 06-09 } \\
\text { Dif. } \\
\text { AIM } \\
-0,03 \\
\end{array}$} & \multicolumn{2}{|c|}{$09-13$} \\
\hline & \multirow{2}{*}{\begin{tabular}{|c|}
$\begin{array}{c}\text { US\$/ } \\
\mathrm{m} 2\end{array}$ \\
1.250
\end{tabular}} & \multirow{2}{*}{$\begin{array}{c}\text { US\$ } \\
56.228\end{array}$} & \multirow{2}{*}{\begin{tabular}{|l} 
AIM \\
9,2
\end{tabular}} & \multirow{2}{*}{\begin{tabular}{|c|}
$\begin{array}{c}\text { US\$/ } \\
\mathrm{m} 2\end{array}$ \\
1.794 \\
\end{tabular}} & \multirow{2}{*}{$\begin{array}{c}\text { US\$ } \\
80.727\end{array}$} & \multirow{2}{*}{\begin{tabular}{|r|} 
AIM \\
9,2
\end{tabular}} & \multirow{2}{*}{$\begin{array}{c}\begin{array}{c}\text { US\$/ } \\
\mathrm{m} 2\end{array} \\
2.439\end{array}$} & \multirow{2}{*}{$\begin{array}{c}\text { US\$ } \\
109.745\end{array}$} & \multicolumn{2}{|c|}{ AIM } & & \multirow{2}{*}{$\begin{array}{c}\begin{array}{c}\text { Dif. } \\
\text { AIM }\end{array} \\
-0,81\end{array}$} & \multirow{2}{*}{\begin{tabular}{|r} 
Dif. \\
AIM \\
4,0
\end{tabular}} \\
\hline & & & & & & & & & 8,3 & 13,1 & & & \\
\hline Palermo & 1.593 & 71.685 & 11,7 & 2.232 & 100.462 & 11,4 & 3.132 & 140.948 & 10,7 & 16,9 & $-0,32$ & $-0,67$ & 5,5 \\
\hline Villa Crespo & 1.200 & 54.022 & 8,8 & 1.664 & 74.886 & 8,5 & 2.214 & 99.618 & 7,6 & 11,9 & $-0,33$ & $-0,91$ & 3,4 \\
\hline \begin{tabular}{|l|} 
Villa \\
Urquiza
\end{tabular} & 1.213 & 54.584 & 8,9 & 1.665 & 74.935 & 8,5 & 2.204 & 99.197 & 7,5 & 11,9 & $-0,42$ & $-0,95$ & 3,4 \\
\hline $\begin{array}{l}\text { Tipo de } \\
\text { ingresos }\end{array}$ & \multicolumn{3}{|c|}{2006 (Octubre) } & \multicolumn{3}{|c|}{2009 (Octubre) } & \multicolumn{4}{|c|}{2013 (Octubre) } & \begin{tabular}{|c|} 
Var. \\
06-09
\end{tabular} & \multicolumn{2}{|c|}{$\begin{array}{c}\text { Variación } \\
09-13\end{array}$} \\
\hline $\begin{array}{l}\text { Ingreso } \\
\text { medio \$ }\end{array}$ & \multicolumn{3}{|c|}{1.571} & \multicolumn{3}{|c|}{2.800} & \multicolumn{4}{|c|}{6.783} & $78 \%$ & \multicolumn{2}{|c|}{$142 \%$} \\
\hline \begin{tabular}{|l|} 
Ingreso \\
medio US\$
\end{tabular} & \multicolumn{3}{|c|}{510} & \multicolumn{3}{|c|}{735} & \multicolumn{2}{|c|}{1.096} & \multicolumn{2}{|c|}{695} & $44 \%$ & $49 \%$ & $-5 \%$ \\
\hline Costo US\$ & \multicolumn{3}{|l|}{3,08} & \multicolumn{3}{|c|}{3,81} & & 6,19 & \multicolumn{2}{|c|}{9,76} & $24 \%$ & $62 \%$ & $62 \%$ \\
\hline
\end{tabular}

FUENTE ELABORADO CON INFORMACIÓN RELEVADA POR LA DIRECCIÓN GENERAL DE ESTADÍSTICA Y CENSOS (MINISTERIO DE HACIENDA, GOBIERNO DE LA CIUDAD DE BUENOS AIRES [GCBA]);

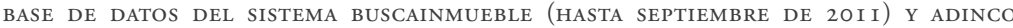
(DESDE OCTUBRE DE 2OII) PARA VALORES COMPRAVENTA; BASE DE DATOS DEL INSTITUTO NACIONAL DE ESTADística y CENSOS (INDEC), ENCUESTA PERMANENTE DE HOGARES PARA INGRESO MEDIO. BANCO CENTRAL PARA COTIZACIÓN DÓLAR

NOTA EN LAS COLUMNAS SOMBREADAS EN GRIS SE ADOPTÓ AL DÓLAR ILEGAL O PARALELO COMO REFERENCIA; EL INGRESO MEDIO Y LAS TASAS DE CAMBIO SON EL PROMEDIO DEL ÚLTIMO TRIMESTRE DE CADA AÑO.

Esta restricción de compra se dio, paradójicamente, en simultáneo con el aumento del ingreso medio en pesos del $142 \%$ en el transcurso de esos cuatro ańos. Sin embargo, el carácter dolarizado del mercado inmobiliario, así como el desdoblamiento entre el valor oficial y el ilegal de esta moneda a partir del reforzamiento del "cepo cambiario", han determinado que el poder de compra en dólares haya disminuido. El acceso libre a la divisa estadounidense se fue restringiendo hasta quedar totalmente imposibilitado hacia mediados de 2012, y el mercado inmobiliario comenzó a regirse desde entonces a partir de los valores del mercado cambiario ilegal. Mientras la cotización del dólar de referencia (el oficial y único) en 2009 era de 3,81 pesos argentinos, para el ańo 2013 el costo del dólar oficial había ascendido a 6,19 pesos, pero el del dólar de referencia para el mercado (el ilegal o paralelo) había ascendido a 9,76 pesos. Según este parámetro, hacia octubre de 2013, con un ingreso medio podían adquirirse 695 dólares, un 5\% menos que en octubre de 2009, cuando se podían comprar 735 dólares. Pero independientemente del poder adquisitivo en dólares (ya sea adoptando la cotización oficial, ilegal o una intermedia), lo cierto es que en el período 2009-2013 el precio de la vivienda por estrenar continuó el desproporcionado ritmo alcista que caracterizó todo el ciclo 
de valorización, aun en los barrios con mayor expansión de la oferta, que vieron incrementar el precio de la vivienda nueva entre un 32\% (Villa Urquiza) y un $40 \%$ (Palermo). Son precisamente estos niveles de valorización los que explican, en lo fundamental, la cantidad adicional de AIM que debe reunirse para la compra de una vivienda tipo.

El inédito esfuerzo monetario que debe realizarse para acceder a la vivienda supuso una fuerte contracción de la demanda inmobiliaria y, como se ha comentado, ha reorientado la estrategia del desarrollo inmobiliario hacia la producción de vivienda de menor tamańo, para intentar mantener cierto nivel de ventas. Para varias personas que aún se encuentran en condiciones de acceder a la vivienda a través de la compra, esta forma de ajuste ha significado una importante renuncia a espacio residencial. Por ejemplo, los 107.000 dólares que se requerían el año 2009 para la compra de un departamento de tres ambientes por estrenar en Caballito, para el ańo 2013 ya no alcanzaban siquiera para la compra de uno de dos ambientes. Pero para muchas familias el notable incremento del precio de la vivienda ha significado la renuncia al mercado de compraventas y el traspaso al mercado de alquileres. En efecto, el proceso de inquilinización acontecido en los años dos mil ha significado un punto de inflexión en la tendencia que venía dándose desde mediados de siglo xx, en cuanto al aumento absoluto y relativo de los hogares propietarios en la СВA $^{16}$. Para otras familias, este encarecimiento de la vivienda significó la renuncia a metros cuadrados del espacio habitacional. Por tal motivo, hogares de igual tamaño han accedido, en los últimos años, a viviendas considerablemente más pequeñas.

A diferencia del mercado de compraventa, los valores locativos del mercado de alquileres rigen en pesos. Este hecho, sumado al aumento del ingreso medio de los últimos años (165\% entre febrero de 2009 y noviembre de 2013), ha determinado que el esfuerzo monetario para alquiler no se haya agravado, como ocurrió en el mercado de compraventa. Por el contrario, la incidencia de la renta de alquiler sobre el ingreso medio llegó a disminuir, especialmente en los barrios que más expandieron su oferta residencial para este mercado, como Palermo y Villa Crespo (tabla 3). Es decir, el incremento del ingreso medio se ubicó por encima del aumento del precio de alquiler de las unidades de vivienda de dos ambientes, cuyo rango de variación osciló entre el 161\% en Almagro y el 90\% en Palermo.

Las mayores restricciones para la compra de vivienda también deben ubicarse en un contexto de ausencia de crédito hipotecario, que en la actualidad se encuentra en los niveles más bajos de los últimos sesenta años. Los requisitos de acceso al crédito dejan a la mayoría de los hogares por fuera del mercado de hipotecas, en primer lugar, por la persistencia del trabajo informal en niveles elevados ${ }^{17}$; en segundo lugar, porque la relación cuota / ingresos excluye a la mayoría de los trabajadores formales ${ }^{18}$; por

16 Entre 1960 y el año 2001, la proporción de hogares inquilinos se redujo del 50\% al 22\%, registrándose la mayor disminución en el decenio 1970-1980 (del 40\% al 25\%). Este ciclo se interrumpe y revierte en el decenio 2001-2010, cuando se registra un aumento de la incidencia de hogares inquilinos en 8 puntos porcentuales (del 22\% al 30\%).

$17 \mathrm{Al}$ tercer trimestre de 2013, la tasa de empleo no registrado (la relación entre el empleo no registrado y el total de los asalariados de 14 y más años) se ubicaba por encima del 35\% (Encuesta Permanente de Hogares [EPH], Instituto Nacional de Estadística y Censos [INDEC], 2014) en la RMBA.

18 Se ha calculado que, para el año 2010, una familia necesitaba entre dos y tres ingresos medio 
último, por las altas de interés que, si bien varían significativamente según la línea de crédito hipotecario, suelen ser elevadas ${ }^{19}$. Por el contrario, en contextos de mercados inmobiliarios desregulados, el desfase entre la oferta y la demanda inmobiliaria que impacta en nuevos alzas de precios es inevitable. En otras palabras, de no mediar políticas e instrumentos de regulación de la oferta de suelo y vivienda, el crédito hipotecario se convierte en un factor extra de valorización inmobiliaria que horada el subsidio y, por lo tanto, genera una transferencia de recursos públicos hacia los propietarios.

TABla 3 Precio promedio de alquiler en pesos de departamentos de 2 ambientes e incidencia en ingresos medio. CBA, febrero de 2009 y 2013

\begin{tabular}{|l|c|c|c|c|c|c|}
\hline \multirow{2}{*}{ BaRrio } & \multicolumn{2}{|c|}{ 2009 (FEBRERO) } & \multicolumn{2}{c|}{ 20I3 (NOVIEMBRE) } & \multicolumn{2}{c|}{ 2009-20I3 } \\
\cline { 2 - 7 } & $\begin{array}{c}\text { PRECIO } \\
\text { ALQUILER }\end{array}$ & $\begin{array}{c}\text { INCIDENCIA } \\
\text { ALQUILER }\end{array}$ & $\begin{array}{c}\text { PRECIO } \\
\text { ALQUILER }\end{array}$ & $\begin{array}{c}\text { INCIDENCIA } \\
\text { ALQUILER }\end{array}$ & $\begin{array}{c}\text { VAR. PRECIO } \\
\text { ALQUILER }\end{array}$ & $\begin{array}{c}\text { DIF. } \\
\text { ALQUENCIA } \\
\text { ALELR }\end{array}$ \\
\hline Agronomía & 975 & $38,0 \%$ & 2.503 & $36,9 \%$ & $157 \%$ & $-1,1$ \\
\hline Almagro & 975 & $38,0 \%$ & 2.544 & $37,5 \%$ & $161 \%$ & $-0,5$ \\
\hline Barracas & 1.050 & $40,9 \%$ & 2.441 & $36,0 \%$ & $132 \%$ & $-5,0$ \\
\hline Caballito & 1.100 & $42,9 \%$ & 2.524 & $37,2 \%$ & $129 \%$ & $-5,7$ \\
\hline Colegiales & 1.050 & $40,9 \%$ & 2.565 & $37,8 \%$ & $144 \%$ & $-3,1$ \\
\hline Flores & 975 & $38,0 \%$ & 2.374 & $35,0 \%$ & $143 \%$ & $-3,0$ \\
\hline Palermo & 1.450 & $56,5 \%$ & 2.755 & $40,6 \%$ & $90 \%$ & $-15,9$ \\
\hline San Cristóbal & 950 & $37,0 \%$ & 2.390 & $35,2 \%$ & $152 \%$ & $-1,8$ \\
\hline Villa Crespo & 1.175 & $45,8 \%$ & 2.395 & $35,3 \%$ & $104 \%$ & $-10,5$ \\
\hline Villa Urquiza & 1.050 & $40,9 \%$ & 2.426 & $35,8 \%$ & $131 \%$ & $-5,2$ \\
\hline Ingreso Medio & 2.564 & & 6.783 & & $165 \%$ & \\
\hline
\end{tabular}

FUENTE ELABORADO CON INFORMACIÓN DE LA DIRECCIÓN GENERAL DE ESTADÍSTICA Y CENSOS (MINISTERIO DE HACIENDA, GOBIERNO DE LA CIUDAD DE BUENOS AIRES [GCBA])

individuales para adquirir una vivienda de dos ambientes con crédito hipotecario. Más precisamente, se requerían 7.376 pesos argentinos, suponiendo un tope del $30 \%$ del peso de la cuota sobre el ingreso, un plazo de financiamiento a 180 meses y un ahorro previo del $50 \%$. Para la adquisición de la misma unidad, pero financiada a 120 meses con un $30 \%$ de ahorro previo, se requería un ingreso de 11.490 pesos (CEDEM, 2012). El ingreso medio individual para el cuarto trimestre de 2010 era de 3.641 pesos.

19 Una forma de dimensionar cómo el costo general del crédito presiona fuertemente sobre los ingresos es comparando el costo mensual de una hipoteca con el precio de alquiler. Hacia el año 2010 , y suponiendo un ahorro previo del $30 \%$ respecto al precio de venta de la vivienda, se requería desembolsar un $80 \%$ más de dinero para cubrir la cuota del crédito en comparación con el precio de alquiler. 


\section{Conclusiones}

En este trabajo se ha analizado el panorama inmobiliario y su relación con el esfuerzo monetario que deben realizar los hogares para acceder a una vivienda formal en la Ciudad de Buenos Aires (Сва) y su contexto metropolitano. La caracterización de este fenómeno ha tenido como finalidad comprender un factor de primera importancia en lo que refiere a las crecientes restricciones de acceso residencial que imperaron a lo largo del ciclo de valorización inmobiliaria 2003-2013.

El alza generalizada de precios del suelo se ha hecho notar fuertemente en los valores de venta de la vivienda y, por lo tanto, en el esfuerzo monetario requerido para su compra. El aumento de la demanda de alquiler se vincula precisamente con las crecientes restricciones de compra de vivienda asociadas a la falta de crédito hipotecario, pero, fundamentalmente, al encarecimiento del suelo urbano. En este contexto, el ciclo de valorización del suelo de la СBA no ha sido indistinto del comportamiento del desarrollo inmobiliario. Por el contrario, la concentración territorial y por categoría de vivienda de la superficie residencial autorizada para construir contribuyó a que las mayores tasas de valorización del suelo urbano se hayan registrado en los barrios preferenciales de la demanda de altos y medianos ingresos, sea para la adquisición de la vivienda como bien de uso, como lugar de inversión para la colocación de excedentes de ganancia, o reserva de ahorro ante eventualidades inflacionarias, devaluatorias o crisis bancaria. Esta dinámica ha primado durante el primer subperíodo del ciclo de valorización, específicamente entre los años 2003 y 2008. Luego, la valorización del suelo retoma su senda de crecimiento, pero con otras características. En primer lugar, porque ya había comenzado a revertirse la tendencia histórica de segmentación del mercado de suelo en su escala metropolitana, al menos en lo que atañe a las intensidades de valorización, achicando sutilmente las tradicionales brechas de precios del suelo entre el norte y sur de la CBA, la primera y segunda corona de la RMBA, y el corredor sur respecto a los demás corredores metropolitanos. En segundo lugar, porque en relación causal a estos cambios del funcionamiento de los mercados de suelo, el desarrollo inmobiliario replantea algunos aspectos de su comportamiento. En términos territoriales, comienza a darse una desconcentración relativa de la cantidad de permisos y superficie autorizados para construir. En la СBA, los cinco barrios que concentraron la mitad de la construcción en el período 2003-2008 han cedido terreno a otros barrios, y el predominio de la vivienda suntuosa de grandes superficies ha dado paso a categorías residenciales de menor tamaño y estándar. En suma, la necesidad de mantener ciertos márgenes de ganancia con un mayor aprovechamiento del suelo ha reorientado la estrategia del desarrollo inmobiliario hacia la producción de vivienda de menor estándar y tamaño, y ya no solo hacia los barrios que habían protagonizado el boom de la construcción en el período 2003-2008. De este modo, en el período 2009-2013 aumentó la incidencia de construcción de vivienda sencilla de uno y dos ambientes por fuera de las áreas tradicionales de alta renta de la ciudad.

Ahora bien, independientemente del comportamiento del desarrollo inmobiliario en ambos subperíodos, lo cierto es que la notable expansión residencial generada no implicó un mejoramiento de las condiciones de acceso a la vivienda 
formal en la СвA. Por el contrario, la cuestión habitacional se ha agravado y los conflictos por el acceso al suelo, la vivienda y la ciudad se han multiplicado. El aumento obsceno de los precios del suelo es parte central de la explicación. Al cóctel de valorización inmobiliaria compuesto por la selectividad de la inversión inmobiliaria, el nivel de actividad y requerimiento de espacio para las actividades económicas, la tasa de interés y colocación de excedentes de ganancia, las decisiones de atesoramiento, la rentabilidad esperada de los proyectos y, fundamentalmente, el comportamiento desregulado del desarrollo inmobiliario, se le debe agregar un nuevo ingrediente: el aumento absoluto y proporcional de la vivienda desocupada. El desacople entre el stock físico y el flujo de oferta de vivienda se ha incorporado así a la larga lista de los factores que ubican el alza de precios del suelo y la vivienda por encima de cualquier índice inflacionario. La información del último Censo en cuanto a la incidencia de la vivienda deshabitada ${ }^{20}$, pone una vez más de manifiesto la imperiosa necesidad de implementar una política integral de vivienda que incorpore instrumentos de generación, movilización y utilización de la oferta de vivienda y regulación del mercado inmobiliario; y ello ya no solo para favorecer el acceso a un techo, sino para garantizar el derecho a la ciudad, desalentando los procesos de segregación residencial, inequidad territorial, ociosidad del suelo, y revirtiendo la perversa situación sociourbana de "casas sin gente" y "gente sin casas". Se requiere, en definitiva, de iniciativas que reorienten el desarrollo inmobiliario para atender la cuestión habitacional desde un criterio de equidad territorial y promover un mejor aprovechamiento de la infraestructura y los servicios existentes.

\section{Referencias bibliográficas}

Baer, L. (2012). Mercados de suelo y producción de vivienda en la Buenos Aires y su Área Metropolitana. Tendencias recientes de desarrollo urbano y acceso a la ciudad. Revista Iberoamericana de Urbanismo, (8), 43-58. Disponible en http://upcommons.upc.edu/ bitstream/handle/2099/13033/08_03_Baer.pdf

Baer, L. (2011). El mercado de suelo formal de la Ciudad de Buenos Aires en su contexto metropolitano. Dinámica de precios de terrenos, desarrollo inmobiliario y acceso a la vivienda en la década de dos mil (Tesis de Doctorado, Facultad de Filosofía y Letras, Universidad de Buenos Aires).

Baer, L. (2008). Crecimiento económico, mercado inmobiliario y ausencia de política de suelo. Un análisis de la expansión del espacio residencial de la Ciudad de Buenos Aires en los 2000. Proyección, 2(5). Disponible en http://bdigital.uncu.edu.ar/3256.

Cosacov, N. (2012). Alquileres e inquilinos en la Ciudad de Buenos Aires. Una radiografía.

Documentos del Laboratorio de Políticas Públicas, Buenos Aires.

20 En el ańo 2010 se relevaron 340.975 viviendas deshabitadas sobre un parque total de 1.425 .840 unidades. La incidencia del $23,9 \%$ coloca a la свA en la cima del ranking de vivienda deshabitada del país, según el último Censo. El salto en este indicador fue tan desfavorable que para el período intercensal 2001-2010 se registró un aumento de la vivienda deshabitada de 132.105 unidades y su incidencia en 8,4 puntos porcentuales. 
Cravino, M. C. (2012). Informalidad y política urbana en Buenos Aires: el retorno de viejas prácticas. Fórum de Direito Urbano e Ambiental, 11(61), 11-25. Disponible en http:// bdjur.stj.jus.br/dspace/handle/2011/44898

Del Río, J. P. (2012). El lugar de la vivienda social en la ciudad: un análisis de la politica habitacional desde el mercado de localizaciones intraurbanas y las trayectorias residenciales de los habitantes (Tesis de Doctorado), Universidad Nacional de La Plata, Facultad de Humanidades y Ciencias de la Educación. Disponible en http://www.memoria.fahce. unlp.edu.ar/tesis/te.464/te.464.pdf

Di Filippo, F. y equipo (2010). Buenos Aires sin techo. Informe sobre la emergencia habitacional en la Ciudad de Buenos Aires. Buenos Aires: Ed. Comisión de la Vivienda de la Legislatura de la Ciudad de Buenos Aires. Disponible en http://es.scribd.com/doc/65498835/ BUENOS-AIRES-SIN-TECHOLa-Ausencia-de-politicas-de-acceso

Duarte, J. (2010). Adquisición de suelo para las políticas de vivienda y regularización dominial. El caso del Conurbano Bonaerense 2003/2008. Research Project, Lincoln Institute of Land Policy. Referencia en http://www.lincolninst.edu/education/research-detail. asp?id=151

Eckert, J. K. (1990). Tasación de la propiedad y administración de la evaluación. Chicago, Ill: Asociación Internacional de Oficiales de la Evaluación.

Herzer, H. (Comp.). (2012). Barrios al sur. Renovación y pobreza en la Ciudad de Buenos Aires. Buenos Aires: Café de las Ciudades.

Hidalgo, R. \& Janoschka, M. (Eds.). (2014). La ciudad neoliberal: gentrificación y exclusión en Santiago de Chile, Buenos Aires, Ciudad de México y Madrid. Santiago de Chile: Serie Geolibros No 19, Instituto de Geografía, Pontificia Universidad Católica de Chile / Departamento de Ciencia Política y Relaciones Internacionales, Universidad Autónoma de Madrid.

,Jajamovich, G. \& Menazzi, L. (2013). Entre la grúa y el globo. Revista Crisis, (18), 28-31.

Jaramillo, S. (2009). Hacia una teoría de la renta del suelo urbano (2a ed. revisada y ampliada). Bogotá: Universidad de los Andes.

Morales-Schechinger, C. (2005). Políticas de suelo urbano, accesibilidad de los pobres y recuperación de plusvalías. Texto correspondiente a la investigación La renta del suelo, las finanzas urbanas y el municipio mexicano, desarrollada en Universidad Nacional Autónoma de México, México. Disponible en sistemamid.com/download. php?a=83936

Morales-Schechinger, C. (2007). Algunas reflexiones sobre el mercado de suelo urbano. Texto nodal del curso Mercados de Suelo Urbano en América Latina, Lincoln Institute of Land Policy.

Rodríguez, M. \& Virgilio, M. (2015). Ciudad de Buenos Aires: políticas urbanas neoliberales, transformaciones socioterritoriales y hábitat popular. Revista de Direito da Cidade, 6(2), 323-348. doi: http://dx.doi.org/10.12957/rdc.2014.13441

Salinas Arreortua, L. A. (2013). Gentrificación en la ciudad latinoamericana: el caso de Buenos Aires y Ciudad de México. GeoGraphos, 4(44), 281-304. Disponible en http://web. ua.es/revista-geographos-giecryal 
Silva, C. (2013). Gentrificación y cambios sociodemográficos en la Zona Sur de la Ciudad de Buenos Aires. 2003-2010. x Jornadas de Sociología, Facultad de Ciencias Sociales, Universidad de Buenos Aires, Buenos Aires, 2013. Disponible en http://cdsa. aacademica.org/000-038/191.pdf

Smolka, M. (1981). Precio de la tierra y valorización inmobiliaria urbana: esbozo para una conceptualización del problema. Revista Interamericana de planificación, 15(60), 70-89.

Szajnberg, D. (2006). El proceso de densificación del tejido residencial en Buenos Aires desde los años noventa (Tesis de Maestría en Planificación Urbana y Regional), Facultad de Arquitectura, Diseño y Urbanismo, Universidad de Buenos Aires.

Trivelli, P. (2006). Algunos antecedentes para un análisis del mercado de suelos urbano. Texto elaborado para el curso Fundamentos para el análisis de los mercados de suelo en América Latina, Lincoln Institute of Land Policy, Santiago de Chile, noviembre 2006.

Vecslir, L. \& Baer, L. (2011). Reestructuración urbana y mercados de suelo en las centralidades metropolitanas de Buenos Aires. Documento presentado en I Congreso Latinoamericano de Estudios Urbanos. Pensar la ciudad, cambiar la ciudad. Los restos de la investigación en América Latina a comienzos de siglo XXI, Universidad General Sarmiento, 24 a 26 de agosto de 2011, Los Polvorines, Buenos Aires.

\section{Otras fuentes documentales}

Adinco Inmobiliaria (2014). Sistema de gestión inmobiliaria. http://adinco.net/frmlogin.aspx Banco Central de la República Argentina (2014). Boletín Estadístico, mayo 2014, Año 55, Nro. 5. Centro de Estudios para el Desarrollo Económico Metropolitano (CEDem) (2012). La otra cara del boom de la construcción y el consumo. Dificultades para el acceso al crédito hipotecario para la compra de viviendas en la ciudad de Buenos Aires. Cuaderno de Trabajo Nro. 13.

Dirección General de Estadísticas y Censos (DGeyc) (2011). Anuario Estadístico Ciudad de Buenos Aires. Ministerio de Hacienda, Gobierno de la Ciudad de Buenos Aires (GCBA).

Dirección General de Registro de Obras y Catastro. Secretaría de Planeamiento, Ministerio de Desarrollo Urbano (MDU). Gobierno de la Ciudad de Buenos Aires (GCBA).

Encuesta Permanente de Hogares (EPH), Instituto Nacional de Estadística y Censos (INDEC), 2014.

Secretaría de Planeamiento (ssplan) (2014). Mercado Inmobiliario de la Ciudad de Buenos Aires. Precio de oferta de venta de terrenos. Unidad de Sistemas de Inteligencia Territorial, Secretaría de Planeamiento, Ministerio de Desarrollo Urbano (MDU). Gobierno de la Ciudad de Buenos Aires (GсвA), abril de 2013. http://www.buenosaires.gob.ar/ planeamiento/publicaciones/mercado-inmobiliario

Secretaría de Planeamiento (ssplan) (2013). Distribución territorial del precio de oferta de los terrenos en la Región Metropolitana de Buenos Aires. Unidad de Sistemas de Inteligencia Territorial, Secretaría de Planeamiento, Ministerio de Desarrollo Urbano (MDU). Gobierno de la Ciudad de Buenos Aires (GCBA), diciembre de 2013.

Zaiat, A. (2014). Insumos difundidos. Página/12. Domingo, 8 de junio de 2014. 